\title{
ESCENARIOS MIGRATORIOS Y GLOBALIZACIÓN EN AMÉRICA
}

\author{
LATINA: UNA MIRADA AL INICIO DEL SIGLO XXI
}

\author{
María da Gloria MARRONI ${ }^{1}$
}

\section{Resumen}

El artículo se sitúa en el debate sobre las características de la "nueva era de la migración", propia de los procesos globalizadores a partir de la segunda mitad del siglo XX. Analiza la cuestión en América Latina en el periodo de la alta globalización (Appadurai, 2007). Sistematiza los flujos migratorios regionales clasificándolos a través de indicadores estadísticos, territoriales y geográficos, agrupándolos en subregiones del continente. Toma como referente las propuestas adoptadas por los organismos internacionales para la clasificación de estos flujos (norte-norte, sur-norte, norte-sur, sursur) con las debidas ponderaciones implicadas en su utilización, basados en la división del mundo entre el norte y el sur. Destaca las características de la migración de latinos a Europa y Estados Unidos y los movimientos interregionales entre las subregiones del continente. Concluye que las tendencias de la alta globalización influencian la dinámica de los movimientos demográficos en el continente y diluyen los límites entre migración regional y extrarregional, fronteriza y no fronteriza, temporal, permanente y de tránsito, pero no los homogeniza. Factores territoriales, socio culturales e históricos de los países latinoamericanos actúan para producir una diversidad que necesita ser estudiada.

Palabras clave: América Latina, globalización, migración, fronteras.

\begin{abstract}
The article feeds the debate on the characteristics of the "new era of migration", typical of global processes in the second half of the twentieth century, analyzing the topic in Latin America during the period of high globalization (Appadurai, 2007). Adopting the proposals of international organizations for flow classification (north-north, south-north, north-south, south-south), but weighing their use regarding the division of the world

\footnotetext{
1 Doctora en Sociología por la Universidad Nacional Autónoma de México. Áreas básicas de interés: sociología de la migración; sociología de género; sociología rural y de la familia; metodologías cualitativas de la investigación. Investigadora-docente del posgrado en Sociología, del Instituto de Ciencias Sociales y Humanidades de la Benemérita Universidad Autónoma de Puebla, México. Correo electrónico: gm09velazquez@hotmail.com
} 
between North and South, the article systematizes regional migration flows by subregions, using statistical, territorial and geographical indicators. It highlights the characteristics of Latino migration to Europe and the United States as well as interregional movements between the subregions of the continent. The conclusion is that high globalization trends to influence the dynamics of population movements on the continent, diluting but not homogenizing the boundaries between regional and extra-regional, border and non-border, temporary, permanent and transit migration. It also points that territorial, cultural and socio-historical factors in Latin American countries act to produce a diversity that needs to be taken into consideration.

Keywords: Latin America, globalization, migration, borders.

\section{Résumé}

L'article est situé dans le débat sur les caractéristiques de la "nouvelle ère de la migration", liée aux procès globalisateurs à partir de la deuxième moitié du XXè siècle. On y analyse la question en Amérique Latine dans la période de la haute globalisation (Appadurai, 2007). On systématise les flux migratoires régionaux en les classant à travers des indicateurs statistiques, territoriaux et géographiques, en les goupant en sous-régions du continent. On prend comme référent les propositions adoptées par les organismes internationaux pour le classement de ces flux (nord-nord, sud-nord, nord-sud, sud-sud) avec les pondérations impliquées dans leur utilisation, sur la base de la division du monde entre le nord et le sud. On met en relief les caractéristiques de la migration de latinos vers l'Europe et les États-Unis ainsi que les mouvements interégionaux entre les sous-régions du continent. Le tout pour conclure que les tendances de la haute globalisation exercent une influence sur la dynamique des mouvements démographiques dans le continent et ils diluent les limites entre la migration régionale et la migration extrarégionale, en deçà et au-delà des frontières, temporelle, permanente et en transit, mais ne les rend pas homogènes. Des facteurs territoriaux, socio-culturels et historiques des pays latinoaméricains contribuent à produire une diversité dont il faut absolument rendre compte.

Mots-clés: Amérique Latine, globalisation, migration, frontières.

\section{Introducción}

El desarrollo de América Latina ha sido una historia de migraciones en sus diversas expresiones; en ella destacan tres grandes desplazamientos poblacionales: la producida por la conquista y colonización europea, la forzosa de esclavos negros y la de los grandes flujos de europeos durante el siglo XIX e inicios del XX. Además, particularidades interregionales, fronterizas o extrarregionales constituyeron también un escenario de movilidad humana que contribuyó de manera importante a la diversidad de su sociedad. América Latina fue entonces un espacio de recepción de migrantes.

A partir de la segunda mitad del siglo XX esta tendencia se reinvirtió y el continente pasó a ser una región expulsora de población. Más que destacar esta tendencia en cuanto un fenómeno migratorio en sí mismo, los análisis se han ubicado en otra dimensión: 
apuntar a la reestructuración mundial a partir del final de la Segunda Guerra Mundial y la transición de la nueva sociedad de posguerra.

En la vorágine de la reconstrucción de la sociedad, después de la enorme catástrofe producida por la conflagración mundial, la migración no ameritaba mayor atención. El sistema capitalista se recomponía y en el proceso las secuelas de la guerra constituían la necesidad más urgente a ser enfrentada. Con excepción de los desplazamientos propios de las operaciones bélicas y posconflicto, los masivos flujos de población perdieron importancia desde los cuarenta hasta los sesenta - década en la que empiezan a despuntar-.

Entonces se conformaron otros flujos, tendencias y dinámicas que exigieron nuevas categorías y maneras de comprender el fenómeno. Muchos autores lo caracterizaron como "la era de la migración" (Castles y Miller, 2004) o "nueva ola de migración" para diferenciarlo de la gran movilidad europea a otros continentes durante el siglo XIX e inicios del XX. En este contexto se ubica la discusión sobre la migración en América Latina en las condiciones actuales, enfoque principal tratado en este artículo.

Empezamos por discutir los supuestos teóricos y metodológicos que permiten encarar la dinámica de la movilidad humana en términos del mundo globalizado en el que se inserta América Latina. Posteriormente, caracterizamos la conformación de los principales flujos migratorios en el continente bajo las siguientes coordenadas: la migración de latinos a Estados Unidos y a Europa, clasificadas como migraciones surnorte. A seguir, abordamos la migración interregional o extrarregional en el continente, propia de los flujos sur-sur. Esta supone una dinámica diferente de las direccionadas de los países subdesarrollados a los desarrollados, a pesar de que los esquemas rígidos de la clasificación bipolar del mundo también han sido cuestionados en el tema migratorio.

Buscamos construir una perspectiva para reflexionar sobre América Latina en sus diferencias y particularidades con una visión más integrada de la cuestión migratoria en el inicio del siglo XXI. Por lo general, las corrientes desde el continente dirigidas al norte (sobre todo las de México y las de los países centroamericanos) han sido tratadas con una perspectiva diferente y distanciada de los procesos ocurridos en América del Sur. Así, nos proponemos enriquecer esta perspectiva que integra en mayor medida los movimientos migratorios en el continente.

\section{La migración globalizada: supuestos teóricos y metodológicos para visualizar la movilidad humana en la actualidad}

Castles y Miller (2004) identifican cinco rasgos diferenciales de "la era de la migración": 1) la globalización de la migración; 2) la aceleración de la migración; 3) la diferenciación de la migración; 4) la feminización de la migración, y 5) la creciente politización de la migración (2004: 20). A su vez, Arango Vila-Belda, (2007) refiere como rasgos distintivos de esta etapa: la enorme diversidad de los flujos, la ruptura de la dicotomía países emisores/receptores, la amplitud de los países implicados en los fenómenos, la aparición de los países de tránsito con una nueva dimensión, el desequilibrio entre la oferta y la demanda de la mano de obra migrante, y la restricción de la movilidad humana en marcos aperturistas comerciales y de integración mundiales.

En esta perspectiva, "la era de la migración" representó más que la movilidad humana en los espacios internacionales entre países a través de flujos dirigidos y hasta promovidos anteriormente por los gobiernos: se desarrolló bajo el modelo del capitalismo neoliberal, 
progresivamente consolidado a medida que el final del siglo XX se aproximaba. Es propio de este modelo, como su nombre dice, la transformación del sistema mundial y de las relaciones entre países y regiones. Retoma, para los nuevos tiempos, las propuestas del antiguo liberalismo: sus partidarios ensalzaban sus virtudes mientras criticaban el intervencionismo estatal en el marco de Estado de Bienestar, su excesiva regulación, rigidez e incapacidad para dar respuesta a las nuevas necesidades del capitalismo o, en otro lenguaje, a las exigencias del desarrollo y progreso humano, como estaban interesados en difundir ideológicamente.

"De acuerdo con la teoría, el Estado neoliberal debería favorecer unos fuertes derechos de propiedad privada individual, el imperio de la ley, y las instituciones del libre mercado y del libre comercio" (Harvey, 2007: 71-72). Las críticas al neoliberalismo desenmascaran la posibilidad de convergencia entre la libertad individual y de la sociedad civil y la libertad del capital y empresarial; más bien, señalan la existencia de varias tensiones y contradicciones en estas dos libertades.

En términos de migración internacional varios elementos ilustran estas contradicciones: la formación de un mercado de trabajo globalizado; la apertura comercial expresada por varios tratados de libre comercio; la libre circulación de bienes, servicios y mercancías que el modelo pone en marcha, y las restricciones al movimiento de la fuerza de trabajo entre las fronteras. A medida que avanzó el final del siglo XX e inició el XXI observamos la expresión de esta contradicción en el problema migratorio y, más recientemente, en el de los refugiados.

Existe un amplio proceso de desfronterización en el funcionamiento de las relaciones económicas y sociales en el mundo, pero al mismo tiempo se incrementan las restricciones a la movilidad de la fuerza de trabajo. La construcción de obstáculos entre países avanza casi al mismo tiempo que se liberan las trabas para la circulación del resto de los factores de la producción y reproducción social. No se trata, como se podría pensar, de la pervivencia de barreras antiguas en el mundo actual: surgen nuevas estrategias del capital para administrar el mercado de trabajo mundial según sus intereses, o para manejar sus consecuentes conflictos.

La cuestión migratoria se transformó en el "problema" migratorio. Más regiones y países están conectados con las trayectorias y proyectos de migrantes, más sujetos tienen la posibilidad de migrar a una región extranjera (Elizalde, Thayer \& Córdova, 2013: 1) y más factores provocan estos desplazamientos y fomentan la atracción de millares de personas para buscar mejores oportunidades de vida fuera de su contexto original. Asimismo, la migración internacional no se ha expandido en la misma proporción que los elementos que la están generando: los 243700236 migrantes existentes en la actualidad constituyen el 3.3\% de la población mundial (United Nations, Department of Economic and Social Affairs, 2015; United Nations, Department of Economic and Social Affairs, Population Division, 2015), un número no muy diferente al de otras épocas de la humanidad, a pesar del alarmismo con el que se difunde usualmente el fenómeno. Dadas las condiciones, la pregunta obligada no es por qué migran, sino ¿por qué no migran más?

En tal sentido podemos afirmar que el crecimiento de los flujos migratorios es muy inferior al crecimiento de las condiciones sociales y económicas que los motivan. La causa por la que las migraciones no crecen en una relación proporcional a las condiciones que las propician, hay que buscarla en la respuesta que ofrecen los Estados receptores (Elizalde, Thayer y Córdova, 2013: $1-2)$. 
Esta respuesta se localiza en el control policial y militar expresado fundamentalmente en los procesos de fronterización para la fuerza de trabajo, señalados anteriormente. Se habla de una inmovilidad involuntaria:

La primera explicación de la limitada movilidad actual — limitada, claro está, a tenor del contexto histórico en que se produce - reside en la infinidad de barreras erigidas por las políticas de inmigración de los países receptores, que por doquier restringen el acceso de inmigrantes y reducen la libre circulación de personas. (Arango Vila-Belda, 2007: 2)

En el recuento del problema se trae también a escena:

Esto que Jamen Hollifield llamó la paradoja liberal de la globalización, nos indica que la mundialización de las migraciones, y el crecimiento sostenido de los flujos migratorios no se está produciendo en virtud de una distención de las fronteras, si no a pesar de su engrosamiento, y endurecimiento de las políticas represivas (Elizalde, Thayer y Córdova, 2013: 2).

Otra contradicción es la existencia de facilidades para emigrar debido al derrumbe de las barreras para ello, pero, al mismo tiempo, la dificultad para inmigrar. Todo este cuadro se manifiesta por el crecimiento de la migración irregular y su manejo.

La gestión de los países receptores basada en una política de seguridad nacional actúa con mecanismos policiacos y represivos de control de las fronteras, criminaliza a los migrantes y fomenta la xenofobia de los nativos. De manera paralela, administra su entrada clandestina de manera subrepticia e informal: la internacionalización del mercado laboral y la necesidad de fuerza de trabajo migrante no pueden ser eliminadas.

Este escenario se complejiza por la composición de los flujos migratorios y las características de sus integrantes en función de su edad, sexo, contexto de procedencia, estatus socioeconómico, nivel educativo, grupo étnico y religioso, estatus jurídico de ciudadanía, acceso a redes y recursos para realizar su proyecto migratorio y expectativa en relación ello. Las luchas para hacer viable este proyecto devienen a menudo en participación política en el contexto actual.

Los orígenes de la situación se pueden ubicar en las décadas de la posguerra, pero la maduración del fenómeno sólo se procesa a partir de los setenta en función de la crisis del capitalismo - cuando el neoliberalismo se impone y expande su radio de acción de manera global - Appadurai (2007) se refiere a esto como alta globalización y la ubica a partir de los noventa. ${ }^{2}$

En América Latina se puede hablar de una migración propia de la alta globalización, cuyos antecedentes se localizan en los años ochenta. Su expresión más visible es el masivo desplazamiento de mexicanos y de otras nacionalidades latinoamericanas a Estados Unidos. También al final del siglo se manifiesta un fuerte movimiento de latinoamericanos en dirección a Europa. El escenario de análisis no estaría completo sin destacar el peso y características de la migración entre los propios países del continente

\footnotetext{
2 "Al referirme a la alta globalización (con algo más que un guiño a la alta modernidad) tengo presente sobre todo un conjunto de posibilidades y proyectos utópicos que se extendieron como un reguero de pólvora por numerosos pueblos, estados y esferas públicas tras el final de la guerra fría. Tales posibilidades se entretejieron en una suerte de tramado doctrinario acerca de los mercados abiertos y el libre comercio, de la expansión de las instituciones democráticas y las constituciones liberales..." (Appadurai, 2007: 1415)
} 
que generalmente es tratada como fronteriza, aunque no se limita a ella. Cualquier tipología de las corrientes demográficas en el continente no puede eludir el referente de la división bipolar del mundo entre el norte y el sur, elemento considerado en el siguiente apartado.

\section{La perspectiva de América Latina y los procesos migratorios entre el norte y el sur}

La división del mundo en categorías dicotómicas, presente desde finales del siglo XIX, sigue hoy como un factor básico en los análisis sociológicos y estudios del desarrollo. Las categorías colonia-metrópoli, desarrollado-subdesarrollado, primer mundo-tercer mundo dominaron el espectro conceptual de los debates políticos y de las ciencias sociales hasta los ochenta del siglo XX. Hacia los sesenta el mundo había sido dividido entre los países del primer, segundo y tercer mundo. La caída del bloque socialista tornó obsoleta la categoría de segundo mundo y, por lo tanto, la clasificación de los países basada en ella. A partir de ahí, una nueva dicotomía se presentó para agrupar a los distintos países: el norte y el sur.

Estas expresiones no tienen un referente espacial en sí mismo, más bien se sirven de la terminología geográfica para negarla. Como bien plantea Muller Mahan: "Los puntos cardinales norte y sur sirven en el debate sobre el desarrollo como metáforas para posicionar grupos de países y regiones en un 'sistema global de coordinadas de desarrollo"” (Muller Mahan, citado en Marroni, 2011: 54), así como fueron posicionadas por el Informe Brant. ${ }^{3}$

Los procesos migratorios propios de la globalización han requerido cada vez más la atención de los estudios para superar los encuadres teóricos-metodológicos apegados casi exclusivamente a la división del mundo señalada. Fue característico de estos enfoques la tendencia a considerarlos de manera homogénea y unidireccional: una trayectoria unilineal de la emigración a la inmigración de los países de origen a los de destino. La migración fue concebida como un movimiento de expulsión-atracción de las regiones pobres a las ricas, del subdesarrollo al desarrollo, del sur al norte. En consecuencia, los sujetos que alimentaban a estos flujos eran tratados indiferenciadamente como una masa vulnerable y empobrecida que se dirigía necesariamente a zonas más prósperas. Esta perspectiva hegemonizó la orientación de los estudios migratorios que florecieron casi paralelamente a su mayor visibilización.

Un informe de la Organización Internacional para las Migraciones (OIM) (2013), sin desechar este enfoque, plantea la necesidad de revisarlo para entender el fenómeno migratorio actual. Clasifica los desplazamientos humanos en cuatro direcciones: nortesur, norte-norte, sur-norte y sur-sur; diversifica así la propuesta metodológica inicial. También las flexibiliza al centrarlas en aspectos del fenómeno usualmente no tratados, como la invisibilización de este último tipo de desplazamiento (sur-sur) debido a su importancia. "De hecho, menos de la mitad del total de los migrantes internacionales se

\footnotetext{
3 "El Informe adopta la terminología que se utiliza en el discurso sobre el desarrollo para clasificar a los países según su situación económica. (...) en términos generales por "Norte" se entienden los países de ingresos altos y por "Sur" los países de ingresos bajos y medianos, de conformidad con la clasificación del Banco Mundial. Sin embargo, esas definiciones tienen limitaciones, ya que las diferentes definiciones de "Norte" y "Sur" producen resultados diversos con respecto a la magnitud y las características de la migración en las cuatro direcciones". (Organización Internacional para las Migraciones, 2013: 36) A pesar de esas críticas, la propia OIM admite la utilidad de esta categorización.
} 
desplaza de Sur a Norte, y prácticamente el mismo número se desplaza entre los países del Sur" (Organización Internacional para las Migraciones, 2013: 36). Señala dicho informe que el estudio de estas corrientes ha sido opacado por los concentrados en los flujos sur-norte, tanto en los debates normativos como en la investigación.

\section{Cuadro 1 \\ Dirección de los flujos migratorios según la clasificación de instituciones internacionales}

\begin{tabular}{|l|l|l|l|l|l|l|l|l|}
\hline & \multicolumn{2}{|l|}{ Sur-Norte } & \multicolumn{2}{l|}{ Norte-Norte } & \multicolumn{2}{l|}{ Sur-Sur } & \multicolumn{2}{l|}{ Norte-Sur } \\
\cline { 2 - 10 } & $\begin{array}{l}\text { Contingente } \\
\text { (miles) }\end{array}$ & $\%$ & $\begin{array}{l}\text { Contingente } \\
\text { (miles) }\end{array}$ & $\%$ & $\begin{array}{l}\text { Contingente } \\
\text { (miles) }\end{array}$ & $\%$ & $\begin{array}{l}\text { Contingente } \\
\text { (miles) }\end{array}$ & $\%$ \\
\hline $\begin{array}{l}\text { DAES/Naciones } \\
\text { Unidas }\end{array}$ & 74.297 & 35 & 53.464 & 25 & 73.158 & 34 & 13.279 & 6 \\
\hline Banco Mundial & 95.091 & 45 & 36.710 & 17 & 75.355 & 35 & 7.044 & 3 \\
\hline PNUD & 86.873 & 41 & 32.757 & 15 & 87.159 & 41 & 7.410 & 3 \\
\hline
\end{tabular}

Fuente: Organización Internacional para las Migraciones (2013: 57).

El cuadro 1 demuestra la importancia numérica de este tipo de flujos a nivel mundial utilizando la clasificación de tres instituciones: el Departamento de Asuntos Económicos y Sociales (DAES) de Naciones Unidas, el Banco Mundial y el Programa de las Naciones Unidas para el Desarrollo (PNUD). ${ }^{4}$ Esta clasificación es también un referente obligado para el estudio de la migración en América Latina, pero no se agota en ello. Los estudios en el continente exigen miradas más puntuales que permitan identificar subregiones, periodizaciones, rasgos nacionales y diferenciaciones étnicas, de género y generacionales, o la utilización de la categoría migración sur-norte de manera exclusiva.

En la imposibilidad de abarcar toda la complejidad migratoria en América Latina, una primera aproximación construye un panorama del fenómeno migratorio en el continente a partir del mapeo de los principales flujos migratorios. Se agrupan por subregiones a partir de indicadores numéricos y territoriales-geográficos: a) México-Estados Unidos, b) Centroamérica y Caribe-Estados Unidos, c) Sudamérica-Estados Unidos o Europa, d )Migraciones fronterizas, y e) Migraciones regionales o extrarregionales no fronterizas intercontinentales.

La migración de latinos a Estados Unidos y Europa: ¿reproducción del modelo de movilidad humana del sur al norte?

\footnotetext{
4 "Las cifras sobre la migración internacional en el Norte y en el Sur difieren según la definición que se utilice." (Organización Internacional para las Migraciones, 2013: 56) No son rigurosamente comparables en función de algunas diferencias entre las tres organizaciones sobre países incluidos en el norte o en el sur.
} 
Estados Unidos es el mayor receptor de migrantes del mundo. Actualmente sus 46627 102 migrantes (United Nations, Department of Economic and Social Affairs, 2015) proceden de todos lugares del planeta; su ajena tradición de recibir extranjeros fue confirmada, renovada y establecida en nuevas bases a partir de los procesos de globalización.

En América Latina se pueden distinguir cuatro puntos de inflexión respecto a la migración a Estados Unidos: a) el desplazamiento de la migración europea y asiática en importancia debido a la disminución de estos flujos y al aumento de la originaria del continente; b) la consolidación de la migración mexicana como el mayor flujo unidireccional a un país de destino y el surgimiento de las corrientes procedentes de Cuba, Puerto Rico y República Dominicana, cuya dinámica se entiende por cuestiones políticas y geográficas de la relación bilateral (no tratado en el presente ensayo); c) el aumento exponencial de los movimientos demográficos propios de la alta globalización que condujo a la creación de la categoría hispanos en el léxico durante los ochenta ${ }^{5}$ y que se constituyó en el escenario del actual debate migratorio en la nación americana, y d) la desaceleración de la migración latinoamericana partir de la crisis del 2008 y cuyas tendencias no están definidas en la actualidad.

El cuadro 2 perfila la importancia de los migrantes latinoamericanos en Estados Unidos en una serie histórica. Se confirma el crecimiento exponencial de esta población a partir de la década de los ochenta del siglo XX, sobre todo en el periodo de la alta globalización, y se observa cómo a partir de 2010 existe una disminución relativa del incremento de esta población.

\section{Cuadro 2 \\ Inmigrantes* latinoamericanos en Estados Unidos, 1970-2014}

\begin{tabular}{|c|c|r|r|r|r|r|}
\hline Región de origen & $\mathbf{1 9 7 0}$ & $\mathbf{1 9 8 0}$ & $\mathbf{1 9 9 0}$ & $\mathbf{2 0 0 0}$ & $\mathbf{2 0 1 0}$ & \multicolumn{1}{c|}{$\mathbf{2 0 1 4}$} \\
\hline Total** & $9,619,302$ & $14,079,906$ & $19,767,316$ & $31,107,889$ & $39,955,673$ & $42,390,705$ \\
\hline Latinoamérica & $1,803,970$ & $4,372,487$ & $8,407,837$ & $16,086,974$ & $21,224,087$ & $21,890,416$ \\
Caribe & 675,108 & $1,258,363$ & $1,938,348$ & $2,953,066$ & $3,730,644$ & $4,000,114$ \\
Centroamérica & 873,624 & $2,553,113$ & $5,431,992$ & $11,203,637$ & $14,763,612$ & $15,034,607$ \\
México & 759,711 & $2,199,221$ & $4,298,014$ & $9,177,487$ & $11,711,103$ & $11,714,489$ \\
Sudamérica & 255,238 & 561,011 & $1,037,497$ & $1,930,271$ & $2,729,831$ & $2,855,695$ \\
& & & & & & \\
\hline
\end{tabular}

\footnotetext{
5 Antes de este periodo no existían latinos formalmente en Estados Unidos: ellos se distinguían por su nacionalidad de origen. La categoría hispano apareció por vez primera en los censos norteamericanos de 1980 e indica la importancia que los latinos como grupo étnico estaban adquiriendo en el país. La definición actual del término es: "The term hispanic and latino are both used to describe people who are of Hispanic or Latino origin or descent". La categoría censal contabiliza a las personas de origen hispano que aparecen en el cuestionario — «mexicano», «puertorriqueño»o «cubano»-, así como los que ,indicaron ser de «otro origen hispano»"”. (Levine. citado en Marroni, 2011: 57) Los términos latinoamericanos o hispanos por veces son utilizados de manera intercambiable, aunque no son sinónimos y por veces las cifras utilizadas por distintas fuentes pueden variar en el caso.
} 


\begin{abstract}
* El término "inmigrantes" (también conocidos como nacidos en el extranjero) refiere a personas que residen en Estados Unidos que no son ciudadanos estadounidenses por nacimiento. Esta población incluye a ciudadanos naturalizados, residentes permanentes legales y ciertos no inmigrantes legales (por ejemplo, personas con visas de estudiante o de trabajo), los admitidos con el estatus de refugiados o asilados, así como las personas que residen de manera ilegal en Estados Unidos.

** Total de inmigrantes procedentes de todos los países del mundo.

Elaboración propia en base a: Migration Policy Institute (s.f.a) y Migration Policy Institute (s.f.b)
\end{abstract}

Las nacionalidades hispanas que se destacan en Estados Unidos son los mexicanos, salvadoreños, cubanos, dominicanos, guatemaltecos, colombianos, hondureños, ecuatorianos y peruanos, aunque casi todos los países del continente tienen algún tipo de representación en aquel país (López y Patten, 2015). México ocupa un lugar no comparable con cualquier otra nacionalidad: representa el mayor flujo migratorio no sólo de América Latina, sino el más constante y masivo del mundo de un país a otro, en este caso a Estados Unidos. Es también el mayor corredor migratorio del mundo, alimentado de manera elevada por el cruce clandestino que deja huellas de todo tipo: los 6.5 millones de mexicanos constituían en el 2010 el 58\% de los 11.2 millones de migrantes irregulares en el territorio norteamericano (Passel y D'Vera, 2011: 10).

El fenómeno más impactante de la migración latinoamericana es el crecimiento de ésta por parte de los centroamericanos, en particular los procedentes del denominado triángulo del norte, Guatemala, El Salvador y Honduras. En el año 2000, cuando estos flujos ya estaban aumentando, había 1580853 migrantes procedentes de estos países, para el 2014 sumaban un total de 2819370 (Migration Policy Institute, s.f.a y s.f.b).

En función del crecimiento de esta migración, las políticas de control de la frontera norteamericana, dirigidas en su origen a detener la migración irregular procedente de México, ampliaron sus metas y extendieron su cobertura. Se verificaron acuerdos entre el gobierno norteamericano y mexicano para la contención de los flujos migratorios procedentes de otras nacionalidades que utilizaban el territorio mexicano como puente para el ingreso a los Estados Unidos. Se empezó a hablar de la otra frontera. Las líneas fronterizas de México con Guatemala $(965 \mathrm{~km})$ y Belice $(278 \mathrm{~km})$ se constituyeron en un nuevo punto de cruce de extranjeros procedentes de Centroamérica y Caribe.

En el caso de estos países, a diferencia de México, no se puede afirmar que las medidas de securitización hayan desestimulado significativamente la migración a Estados Unidos. Más bien, en la dialéctica control-porosidad de esta frontera, la economía criminal y la industria de la migración, en colusión con autoridades de los países involucrados en el tránsito de los migrantes, "administran" los flujos con sendas ganancias a costa de su explotación y la violación a sus derechos humanos.

La unidireccionalidad a Estados Unidos en el caso de Sudamérica se pierde, a diferencia de la subregión anterior, para dar paso a una bifurcación en donde se alza Europa, además de Estados Unidos, como otro destino significativo en el primer mundo (cuadro 3). Las tendencias de los países de la subregión no son homogéneas. Algunos países mantienen un evidente predominio de su desplazamiento a Estados Unidos (México, Cuba, Guatemala, El Salvador y Honduras), en otros la movilidad se da mayormente a Europa (Argentina, Ecuador y Bolivia); mientras que en otros las diferencias de movilidad entre estos dos destinos no son tan evidentes. El caso más connotado de la migración latinoamericana a Europa es la procedente de la región andina.

El vínculo histórico entre los países de origen y de destino, relacionado con el proceso de colonización y posteriormente con la primera oleada migratoria del siglo XIX e inicio del XX de los europeos al continente (en especial a los países del cono sur), puede estar 
en la base de estas tendencias actuales de desplazamiento continental. ${ }^{6}$ Refuerza esta tesis el hecho de que la migración latinoamericana se concentra predominantemente en España (2 616 000) (Organización Internacional para las Migraciones, Oficina Regional para el Espacio Económico Europeo, Unión Europea y OTAN, 2012: 36). La identidad culturalidiomática ha sido apuntalada como el principal factor de ello. Estas raíces podrían constituir sólo un elemento de explicación en contextos específicos, pero no ofrecen una comprensión suficiente de la direccionalidad de las varias corrientes entre Latinoamérica y Europa.

\section{Cuadro 3}

Principales nacionalidades latinoamericanas en la Unión Europea, 2010

\begin{tabular}{|c|c|c|c|}
\hline País de origen & $\begin{array}{c}\text { Población } \\
2011 \\
\text { (millones) }\end{array}$ & $\begin{array}{c}\text { Stock en los } \\
27 \text { países de } \\
\text { la UE }\end{array}$ & Países con mayor stock de personas en la UE \\
\hline Argentina & 40.7 & 388947 & España (331173), Italia (16243), Francia (11171) \\
\hline Bolivia & 10.1 & 293241 & España (2 431), Alemania (2 148) e Italia (1 231) \\
\hline Brasil & 196.6 & 443806 & $\begin{array}{l}\text { España (162 205), Portugal (70 350) y el Reino Unido } \\
(57 \text { 245) }\end{array}$ \\
\hline Chile & 17.27 & 154418 & España (76 268), Suecia (29 805) y Francia (14 615) \\
\hline Colombia & 46.9 & 485859 & España (375 710), Francia (24 806) e Italia (23 262) \\
\hline Cuba & 11.2 & 145890 & España (105 748), Italia (18 959) y Alemania (11 726) \\
\hline Ecuador & 14.7 & 632252 & España (519 123), Italia (95 226) y Alemania (5 908) \\
\hline El Salvador & 6.2 & 22663 & España (8 130), Italia (7 989) y Suecia (2 899) \\
\hline Guatemala & 14.8 & 13813 & España (6 699),Francia (1 745) y Alemania (1 037) \\
\hline Honduras & 7.7 & 30910 & España (27 059), Alemania (896) e Italia (822) \\
\hline México & 114.8 & 90917 & España (48 483), Alemania (14 208) y Francia (7 245) \\
\hline Nicaragua & 5.9 & 15357 & España (11 540), Alemania (937) y Suecia (564) \\
\hline Paraguay & 6.6 & 83457 & España (78 528), Alemania (1 286) e Italia (1 192) \\
\hline Perú & 29.4 & 317922 & España (184 832), Italia (92 001) y Alemania (12 620) \\
\hline
\end{tabular}

\footnotetext{
${ }^{6}$ Las teoría migratorias basadas en los enfoques de los sistemas mundiales afirman que el vínculo entre colonizados y colonizadores implica desplazamientos mutuos y que estos últimos en la actualidad tienden a desplazarse a sus antiguas metrópolis. Por otro lado, la primera ola migratoria que llevó miles de europeos y asiáticos al continente americano también se sirve de esta premisa para explicar "el retorno" de los descendientes de esos primeros migrantes a la tierra de origen de sus ancestros. Además de la migración a Europa de latinoamericanos, otro ejemplo es la migración de los nikkeis (brasileños descendientes de japoneses) y peruanos en la misma situación, quienes han conformado flujos significativos a este país en el periodo estudiado.
} 


\begin{tabular}{|l|l|l|l|}
\hline $\begin{array}{l}\text { República } \\
\text { Dominicana }\end{array}$ & 10.05 & 173831 & España (130 832), Italia (24 174) y Alemania (7 817) \\
\hline Uruguay & 3.4 & 111020 & España (99 666), Suecia (2 812) e Italia (2 175) \\
\hline Venezuela & 29.4 & 222548 & España (164 239), Portugal (31 519) e Italia (6 786) \\
\hline
\end{tabular}

Elaboración propia en base a: Organización Internacional para las Migraciones, Oficina Regional para el Espacio Económico Europeo, la Unión Europea y la OTAN (2012).

Los escenarios propios de la alta globalización han configurado los circuitos migratorios de algunos países del "Nuevo" continente "al Viejo". Entre los elementos que ilustran esta aseveración se destacan: a) el crecimiento exponencial de estos flujos a partir de la década de los noventa; b) la facilidad para los latinoamericanos de ingresar a estos países, inclusive sin la necesidad de visados especiales; y c) la vinculación de la ofertademanda de trabajo femenina que a partir de la integración del mercado laboral entre los dos continentes generó redes migratorias que reproducían el proceso.

Este crecimiento despertó alarma en los países receptores y las primeras medidas de control, como lo fue la exigencia de visados para el ingreso de determinadas nacionalidades en el espacio Schengen de la Unión Europea a partir del final de la primera década del siglo XX. Actualmente, los escenarios de la migración latinoamericana a Europa son inciertos. La coyuntura de la globalización se acrecienta con la situación específica de los países de envío y de recepción de migrantes, así como la crisis observada en los países centrales a partir de 2008. También la presencia de fuertes conflictos en torno a la cuestión migratoria y de refugio a nivel mundial impactará las corrientes migratorias específicas intercontinentales, en las cuales se encuentra inserta la movilidad humana en el caso de América Latina.

\section{La migración sur-sur en América Latina}

Tampoco en el continente americano la migración sur-sur ha recibido la importancia debida. Estos desplazamientos se encuadraron usualmente como movimientos fronterizos, muchas veces pendulares o circulares y centrados en la cuestión de los cruces entre territorios de dos países. Su problemática ha sido abordada a menudo como una cuestión de línea y de importancia local a lo que se agregaban explicaciones particulares, coyunturales o de lazos históricos, con poca transcendencia fuera de estos ámbitos.

En América Central, estos desplazamientos siguen en parte este patrón; en todos los países de esta región se localizan semejantes movimientos. La migración guatemalteca a México es añeja y persistente, vinculada a la incorporación temporal de jornaleros en las fincas cafetaleras de Chiapas. También en el sector de servicios, sobre todo de la industria turística, relacionada a la explotación sexual de mujeres, de menores y la trata de personas se consolidó este tipo de movimiento en las zonas limítrofes entre los dos países

Las transformaciones recientes en la dinámica migratoria diluyeron este perfil característico de migración fronteriza, ligada a la demanda de trabajo temporal o movimientos pendulares, con el incremento a la migración de tránsito — vía terrestreen dirección a Estados Unidos. El circuito incluye diversas rutas por el territorio salvadoreño, hondureño, guatemalteco y mexicano; a veces se localizan itinerarios a 
través del Caribe (con intersecciones marítimas) o de Sudamérica (que cruzan fronteras colombianas, panameñas, ecuatorianas, venezolanas y brasileñas).

También la modalidad de la migración de tránsito puede tornarse permanente: en ciertos casos la situación se prolonga por años y genera una conflictividad en los territorios en donde opera. La indefinición de los límites entre migraciones fronterizas, de tránsito y permanente constituye uno de los rasgos que configuran los procesos de movilidad humana en la globalización.

En América del Sur las coordenadas para análisis de las corrientes migratorias sur-sur tienen otras características, desdobladas a partir de la reconfiguración histórica de los movimientos regionales insertos en la globalización. Un elemento mediador en esta dinámica se relaciona con las iniciativas de los países latinoamericanos para construir bloques regionales, así como la creación de instituciones para ello (Mercado Común del Sur, MERCOSUR; Unión de Naciones Suramericanas, UNASUR; Alianza Bolivariana para los Pueblos de Nuestra América-Tratado de Comercio de los Pueblos, ALBA-TCP; Comunidad de Estados Latinoamericanos y Caribeños, CELAC, entre otras) que permitan insertarse más favorablemente en los escenarios mundiales. En este contexto, se presenta el debate sobre la eliminación de las fronteras y la libre circulación de las personas en el continente.

Estas iniciativas coinciden con el aumento de la movilidad de la población por los países de la región, el desigual nivel de desarrollo entre ellos y el crecimiento de la demanda del mercado de trabajo en las naciones con economía emergente. Estos elementos contribuyeron a la necesidad de replantear la agenda de los gobiernos en el tema.

En cuanto al comportamiento del fenómeno migratorio interregional en el continente - a pesar de discrepancia en los datos - hay una amplia coincidencia sobre su naturaleza y tendencias recientes: a) la importancia histórica y continua de las migraciones fronterizas, pero que no se limita a ellas; b) la predominancia de los desplazamientos de tipo laboral asociados a factores de tipo histórico y cultural de larga presencia; c) la existencia de países fundamentalmente receptores de población migrante y otros expulsores; d) la existencia de varios países que son simultáneamente contexto de origen, de destino y de tránsito migratorio ;e) la diversidad en la composición de los flujos; y f) las nuevas modalidades de circularidad y del retorno, y con ello la quiebra de la unidireccionalidad anterior de algunas rutas y su diversificación.

En América del Sur, Argentina es considerada la mayor nación receptora de migrantes: en su territorio se asienta un gran número de ellos procedentes de casi todos los países de esta zona. Los bolivianos son la nacionalidad predominante que ha construido numerosos asentamientos en el país, ocupado nichos en el mercado de trabajo y colonizado áreas agrícolas del territorio; se constituyeron como un grupo étnico con importantes espacios socio culturales en el país. También se expandieron de manera significativa por otros países del continente, como Brasil y Chile.

A diferencia de Argentina, Venezuela, el segundo país latinoamericano de destino de los migrantes, no presenta diversidad de nacionalidades de origen en su territorio. La bonanza derivada de su explotación petrolera ha sido un elemento motivador para el desplazamiento a su territorio de ciertos sectores especializados en esta actividad, pero su carácter de país huésped es definido por la masiva presencia de colombianos $(494,325)$ (United Nations, Department of Economic and Social Affairs, Population Division, 2015). Se trata de un movimiento singular de una población afectada por conflictos internos de larga duración. En las condiciones actuales, Colombia es el país que 
ejemplifica de manera contundente la presencia de refugiados y desplazados (inclusive internos) en el continente.

En América del Sur, Bolivia, Colombia, Ecuador, Paraguay y Perú mantienen un claro perfil emigratorio (Organización Internacional para las Migraciones, 2012: 19). El continente es un laboratorio propicio para observar la nueva dinámica emigración/inmigración, característica de la globalización y que complejiza y diversifica los flujos: varios países son simultáneamente emisores y receptores de población extranjera. Brasil y Chile son los ejemplos más sobresalientes de este fenómeno.

Finalmente, el análisis nos sugiere la existencia de ciertos patrones particulares que se podrían considerar inclusive atípicos. En el continente se destacan: el corredor migratorio Nicaragua-Costa Rica en América Central; la paradoja de la inmigración/emigración de Paraguay y la diversidad de estrategias masivas de emigración de haitianos.

El corredor Nicaragua-Costa Rica es un caso sobresaliente de migración sur-sur. El terremoto de 1972 en Managua y la Guerra Civil configuraron un cuadro diferente de movilidad poblacional añeja y anterior de los nicaragüenses en dirección a Costa Rica: la de los refugiados ecológicos y de guerra. A partir de los noventa, con la pacificación del país, sin un cambio sustancial en las condiciones ancestrales de pobreza y de control autoritario, así como las paralelas transformaciones de la economía costarricense, se desarrolla un cuadro sobresaliente de la migración sur-sur basada en la migración laboral neoliberal y de complementariedad de mercados de trabajo. Su carácter ejemplar reside en la relación población nativa/extranjera: se calcula que existen entre 300000 a 500000 mil nicaragüense asentados en Costa Rica, país con una población de 4937755 habitantes. A pesar de las imprecisiones de las cifras, esta correlación demográfica implica alteraciones profundas en la estructura étnica, demográfica, social y económica, a la par de manifestaciones xenofóbicas implícitas en la expresión "nicas", como se designa a los nicaragüenses en este país.

La paradoja del caso paraguayo reside en que uno de los países más pobres del continente y expulsor neto de población — sobre todo de mujeres y a los países vecinostambién es receptor importante de extranjeros. Semejantes contradicciones se explican por la presencia de los brasiguaios (población de origen brasileño), asentada en territorio paraguayo y cuyas estimaciones son variadas (cerca de 500000 brasiguaios actualmente). Originalmente campesinos desplazados por la construcción de la presa de Itapiú en los setenta, aprovecharon la oferta de tierra barata en el vecino país para colonizar la región Este. La posterior facilidad para la adquisición de tierras para los extranjeros por parte del gobierno de Paraguay coincidió con la expansión del cultivo del "oro verde", la soya, y el desarrollo de la ganadería. Se impuso la ampliación del latifundio controlado por empresarios brasileños en la lógica neoliberal agroexportadora de la producción de commodities, incluso no respetan la legislación que les prohíbe a los extranjeros adquirir o usufructuar tierras en territorio paraguayo. Este proceso, a su vez, provocó la expulsión de los campesinos nativos empobrecidos de sus tierras, desempleo rural y degradación ambiental. Se generaron fuertes enfrentamientos, incluidas las invasiones de tierras por parte de estos campesinos y un rechazo a los brasiguaios, ¿un conflicto de clase disfrazado de étnico?

La disputa colonizadora por el territorio de La Española entre dos nacionalidades dejó profundas huellas en las poblaciones de esos territorios caribeños. Ya en el siglo XX las dictaduras en ambos países, República Dominicana y Haití, profundizaron las agresiones a sus poblaciones, degradaron sus condiciones de vida y perpetuaron los conflictos entre los originarios de cada uno de sus países. Posteriormente, el diferente grado de desarrollo 
entre ambos, con el empobrecimiento acentuado de los haitianos y la demanda de trabajo en nichos de la República Dominicana, generaron sendas migraciones de estos últimos, inestables a veces, requeridas o rechazadas y controladas en otras. El terremoto de 2010 rompió este precario equilibrio y desbordó la situación por el masivo desplazamiento de haitianos ocasionado por la catástrofe. Su volumen en el territorio de la República Dominicana - estimados en 480000 personas - proporcionó un argumento para medidas antimigrantes contra ellos, con amenazas y expulsiones del país. Además, República Dominicana se ha negado sistemáticamente a otorgar nacionalidad a los dominicanos descendientes de haitianos nacidos en su territorio. Como tampoco Haití los reconoce como sus ciudadanos, se crea un numeroso contingente, sobre todo de jóvenes apátridas, que viven en un limbo jurídico administrativo y a quienes se les niega un derecho fundamental: tener una nacionalidad. Los haitianos respondieron buscando otras posibilidades migratorias. Estados Unidos, un destino tradicional para ello, no ha sido suficiente para resolver su demanda de visado y refugio. La nueva alternativa encontrada fue Brasil.

Brasil tenía presencia en el país desde 2004 a través de la Misión de las Naciones Unidas para la estabilización de Haití (Minustah). Cuando se presentó el terremoto en 2010 la respuesta del gobierno federal brasileño fue solidaria; se concretizó a través de la propuesta de otorgamiento de visas de emergencia y humanitarias. La solución no fue lo suficientemente ágil delante de la magnitud de la tarea y la oposición de algunos gobiernos locales dificultó la entrada legal de los haitianos en el país. Entonces, parte de los migrantes han optado por entrar a través del territorio amazónico en la frontera con Perú (Nogales Vasconcelos y Botega, 2015). Una estimación, reconocida como inexacta, admite la presencia de entre 20000 a 40000 haitianos en Brasil (Ribeiro de Oliveira, 2015: 145). Gran parte de ellos se encuentran en situación precaria y caótica por la imposibilidad del estado brasileño de dar un cauce adecuado a la situación, y atender e integrar a esta población, aunado a la presencia de un fuerte racismo en muchos contextos locales. El pueblo haitiano, el país más pobre del continente, lleva a los lugares donde busca refugio y protección la tragedia que lo ha acosado históricamente.

\section{Una reflexión final}

¿Son atípicos los casos señalados? Una mirada detallada en ellos proporciona otras posibilidades de análisis: cada proceso migratorio presenta sus particularidades. La homogenización de los patrones migratorios — propios de esquemas teóricos basados exclusivamente en la internacionalización del mercado de trabajo, la globalización y el desplazamiento unidireccional del norte al sur- debe ser matizada y revisada. La identificación de tendencias generales a nivel macro y la diversidad a nivel micro no son contradictorias y hasta pueden ser complementarias.

En América Latina, las movilidades regional y extrarregional a Europa y a Estados Unidos producen escenarios variados y combinados. Y, aunque se visualiza poco todavía, algunos países, como Argentina y Brasil, son también receptores de migrantes procedentes del norte. ¿Una nueva versión de la migración transoceánica que atrajo millones de europeos al continente en la primera ola de migración? Además, el 
asentamiento, según las palabras de Larry Rubin, de una comunidad americana que "representa a los dos millones de norteamericanos que vivimos en México (...): hay mexico-americanos y americanos que se vinieron a vivir a México, y también hay mexicanos que tuvieron hijos en Estados Unidos y se regresaron al país" (Rubin, 2015), obliga a una reflexión sobre los flujos migratorios actuales de norte a sur.

Las tendencias globalizadoras imprimen un perfil propio en muchas situaciones, pero no se imponen de manera autónoma y ajena a las dinámicas del continente y de los distintos países. De ahí la importancia de deshacernos de esquemas predeterminados para entender mejor la realidad en sus múltiples dimensiones.

\section{Bibliografía}

Appadurai, Arjun (2007). El rechazo de las minorías. Ensayo sobre la geografía de la furia. Barcelona, Tusquets Editores.

Arango Vila-Belda, Joaquín (2007). "Las migraciones internacionales en un mundo globalizado", Vanguardia dossier. Inmigrantes, el continente móvil, № 22, pp. 6-15.

Castles, Stephen y Miller, Mark J. (2004). La era de la migración. Movimientos internacionales de población en el mundo moderno. México, Miguel Ángel Porrúa, Universidad Autónoma de Zacatecas, Cámara de Diputados LIX Legislatura, Fundación Colosio, Secretaría de Gobernación, Instituto Nacional de Migración.

Elizalde, Antonio; Thayer Correa, Luis Eduardo y Córdova, María Gabriela (2013). "Prólogo. Migraciones sur-sur: paradojas globales y promesas locales", Polis. Revista Latinoamericana, $\mathrm{N}^{\mathrm{o}} 35$, pp. 1-6.

Harvey, David (2007). Breve historia del neoliberalismo. Madrid, Akal.

López, Gustavo y Patten, Eileen (2015). The Impact of Slowing Immigration: ForeignBorn Share Falls Among 14 Largest U.S. Hispanic Groups. Washington, D.C.: Pew Research Center.

Marroni, María da Gloria (2011). "Latinoamérica en la geografía migratoria mundial: nuestro sur en el norte”, en Villafuerte Solís, Daniel y García Aguilar, María del Carmen 
(coords.): Migración, seguridad, violencia y derechos humanos. Lecturas desde el sur. México, Universidad de Ciencias y Artes de Chiapas, Miguel Ángel Porrúa, pp. 51-77.

Migration Policy Institute (s.f.a). United States. Immigrant Population by Country of Birth, 1960-1990, documento electrónico: http://www.migrationpolicy.org/programs/data-hub/charts/immigrants-countries-birthover-time? width=1000\&height=850\&iframe=true, acceso 10 de junio de 2016.

Migration Policy Institute (s.f.b). United States. Immigrant Population by Country of Birth, 2000-Present, documento electrónico: http://www.migrationpolicy.org/programs/data-hub/charts/immigrants-countries-birthover-time? width=1000\&height=850\&iframe=true, acceso 10 de junio de 2016.

Nogales Vasconcelos, Ana María y Botega, Tulia (2015). Política migratória e o paradoxo da globalização. Porto Alegre, EDIPUCRS, Pontifícia Universidade Católica do Rio Grande do Sul y Centro Scalabriniano de Estudos Migratórios.

Organización Internacional para las Migraciones (2012). Panorama migratorio de América del Sur 2012. Buenos Aires, Organización Internacional para las Migraciones.

Organización Internacional para las Migraciones (2013). Informe sobre las migraciones en el mundo 2013. El bienestar de los migrantes y el desarrollo. España, Organización Internacional para las Migraciones.

Organización Internacional para las Migraciones, Oficina Regional para el Espacio Económico Europeo, Unión Europea y OTAN (2012). Rutas y dinámicas migratorias entre los países de América Latina y el Caribe (ALC) y entre ALC y la Unión Europea. Bruselas: Organización Internacional para las Migraciones, Oficina Regional para el Espacio Económico Europeo, Unión Europea y OTAN.

Passel, Jeffrey S. y D’Vera, Cohn (2011). Unauthorized Immigrant Population: National and State Trends, 2010. Washington, DC: Pew Hispanic Center. 
Perasso, Valeria (2010). “QQuiénes son los "brasiguayos"?”, BBC Mundo, 23 de septiembre.

Rubin, Larry (2015, octubre). Entrevista concedida a Ruiz Healy. Fragmentos disponibles en: http://www.radioformula.com.mx/notas.asp?Idn=538858\&idFC=2015, acceso 2 de junio de 2016.

Sánchez, María Esperanza (2010). "Una población sin patria en República Dominicana", $B B C$ Mundo, 7 de junio.

Ribeiro de Oliveira, Antônio Tadeu (2015). “Os invasores: as ameaças que representam as migrações subsaariana na Espanha e haitiana no Brasil", REMHU. Revista Interdisciplinar da Mobilidade Humana, Año XXIII, No . 44, pp. 135-155.

United Nations, Department of Economic and Social Affairs (2015). Trends in International Migrant Stock: The 2015 revision, United Nations database. New York, United Nations, Department of Economic and Social Affairs. Documento electrónico: http://www.un.org/en/development/desa/population/migration/data/estimates2/estimates

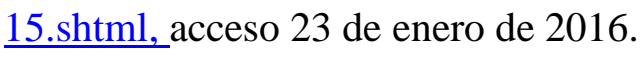

United Nations, Department of Economic and Social Affairs. Population Division (2015). World Population Prospects: The 2015 Revision, United Nations database. New York, United Nations. Documento electrónico: http://esa.un.org/unpd/wpp/Download/Standard/Population/ (acceso 3 de marzo de 2016. 